\title{
The impact of participation in music on learning mathematics
}

\author{
Sylwia Holmes* and Susan Hallam \\ UCL Institute of Education, University College London
}

\begin{abstract}
Music psychologists have established that some forms of musical activity improve intellectual performance, spatial-temporal reasoning and other skills advantageous for learning. In this research, the potential of active music-making for improving pupils' achievement in spatialtemporal reasoning was investigated. As spatial-temporal skills are considered to be high-level mathematical abilities, this study also aimed to explore if learning music might have an effect on pupils' achievement in mathematics, and whether spatial-temporal reasoning plays a role in this process.

The study had a quasi-experimental design in which groups of children aged 4 to 7 participated in a music programme containing a variety of musical, predominantly rhythmical, activities. Parallel classes made up control groups. Throughout the intervention, pupils' attainment in mathematics, reading, writing and spatial-temporal reasoning was recorded and compared between the music and control groups.

The findings of the project supported the hypothesis that music instruction has an impact on the development of spatial-temporal skills. A statistically significantly greater progression was observed in most of the intervention groups, as compared in all periods of measurement to the control groups. The attainment in general mathematics did not always differ between the intervention and control groups but the analyses provided evidence of a consistent and statistically significant enhancement in learning mathematics between the youngest participants of the programme. This knowledge could inform pedagogical practice, while further research in this area could offer more insight into the association between music and mathematics.
\end{abstract}

Keywords: music; mathematics; spatial skills; rhythm; attainment

\section{Introduction}

Music psychologists have established that some forms of musical activity might stimulate the improvement of intellectual performance, spatial-temporal reasoning and other skills advantageous for learning (Hallam, 2000; Hallam et al., 20I I; Hallam, 20I5; Rauscher, 2002; Schellenberg, 2004; Costa-Giomi, 1999; Graziano et al., 1999). Many studies have concentrated on testing children's spatial-temporal skills. There is strong evidence that spatial-temporal reasoning can be improved by musical training, in particular rhythmic instruction enhanced the development of these skills (Rauscher et al., 1993a; Rauscher et al., 1997; Hetland, 2000; Rauscher and Zupan, 2000; Rauscher, 2003; Rauscher et al., 2005; Rauscher and Hinton, 20I I; Hallam, 20I5). For example, in a series of studies, Rauscher explored the relationships between participation in a variety of musical activities and spatial-temporal reasoning, and the findings pointed to the rhythmic instruction having the most pronounced effect. There is also evidence

\footnotetext{
* Corresponding author - email: s.holmes@ucl.ac.uk

(C) Copyright 2017 Holmes and Hallam. This is an Open Access article distributed under the terms of the Creative Commons Attribution Licence, which permits unrestricted use, distribution and reproduction in any medium, provided the original author and source are credited.
} 
that active engagement with music can improve intelligence. For instance, Schellenberg (2004) examined changes on an IQ test and a standardized test of academic achievement after a programme of musical activities. The findings showed a small increase in IQ in those groups who did keyboard or voice training compared to drama or control groups. When other cognitive abilities have been tested, for instance pictorial memory (Rauscher and Zupan, 2000), spatial recognition (Rauscher et al., 1993b; Rauscher et al., 1997) and number recall (Rauscher and LeMieux, 2003), there has been no significant improvement.

Several studies have assessed whether active engagement with music has an impact on mathematics. Gardiner et al. (1996) found that after seven months of supplementary music lessons, children had higher scores on standardized mathematical tests than control groups. Similar findings were established in a study where children were divided into four groups receiving keyboard and spatial-temporal training on the computer, computer training with English instruction, computer training or no programme at all (Graziano et al., 1999). Rauscher and Zupan (2000) found that children who started keyboard lessons at the age of 3, scored higher on spatial-temporal and arithmetic tests throughout two years of training, and even two years after the instruction was terminated. More recently, Rauscher and LeMieux (2003) found that children who received keyboard lessons, singing training or rhythmic instruction, scored higher than controls in arithmetic tests, with the rhythm groups scoring higher on sequencing and arithmetic tasks.

A study by Neville and colleagues (2008) examined the differences in outcomes between four groups of preschoolers who participated in musical activities, attention-enhancing activities or no training. The authors expanded the range of musical activities used in the study. After eight weeks of intervention, which included listening to music, making music, moving to music and singing, a statistically significant change was recorded in numeracy for the music group and the group receiving training in enhancing attention. Children from the music group performed especially well in verbal counting and estimating magnitudes. Rauscher and Hinton (20II) studied children younger than 7 who had received music instruction and concluded that through the intervention spatial-temporal skills and numerical skills improved more in children who participated in music training compared to controls. The impact persisted for two years after the programme ended.

Although much of the academic literature points to the positive impact of participating in musical activities on learning mathematics, there are also examples of studies where such an effect was not observed. Two experiments by Rickard et al. (20I2) revealed inconclusive results. The first was based on a music programme already existing in a school and involved students aged 10 to 13. Comparisons of drama, art and music groups showed greater improvement within the music group compared to other groups in a non-verbal IQ test but not in academic achievement. The second intervention was provided externally over six months and included a variety of musical activities. Three groups took part in the intervention: music, drama and another additional activity. Students from the music group achieved better results in mathematics but this effect was also observed in the drama group. Costa-Giomi (2004) studied children aged 9 to 10 who received three years of weekly individual piano lessons. Self-esteem and musical understanding were greater for the music group but their achievement in mathematics and English, as measured by standardized tests, was no different from the control group. Similarly, in a study by Rafferty (2003) no effect of the music programme on attainment in mathematics was observed. Yang and colleagues (20I4) recorded a correlational relationship between the music training and mathematics but it did not appear to be causal.

Studies in this field have concentrated on children and attempted to establish at what age the impact might be most prominent. For instance, Rauscher et al. (1993b; 1997) found a 
positive enhancement of spatial reasoning in children as young as 3. Other studies (Costa-Giomi, 1999; Costa-Giomi, 2000; Graziano et al., 1999; Gardiner et al., 1996; Rauscher and Zupan, 2000; Rauscher, 2002, Rauscher and LeMieux, 2003; Schellenberg, 2004) involved children of preschool or early primary school ages. Their findings suggest that the earlier the training started, the greater the increase in spatial abilities. This raises the question as to whether there is an age limit past which such a relationship will not exist. The oldest children to participate in such research were 9 (Costa-Giomi, 1999; Graziano et al., 1999). Their performance still improved after learning to play the piano or learning the keyboard, compared with computer lessons.

Spatial-temporal abilities are of particular interest in this study, as they may be a bridge between learning music and mathematics. Rauscher et al. (1993a) defined spatial-temporal reasoning as 'the ability to transform mental images in the absence of a physical model'. Spatialtemporal reasoning involves mentally imagining and manipulating shapes, often without the presence of physical objects. Spatial-temporal reasoning allows individuals to create mental imagery, develop patterns that can change in space and time, and visualize problems and potential solutions. Spatial-temporal skills are widely used in many levels of mathematical thinking, and their development is considered a strong predictor of achievement in mathematics in primary school and other stages of education (Jordan et al., 2008; Geist et al., 2012; Booth and Siegler, 2008). From a very early age, these abilities are utilized not only in geometry, but in a range of mathematical operations, such as number sense and understanding mathematical operations, the ability to choose and use strategies in problem solving, creating internal representations of physical objects and manipulating them to find a solution, and the use of spatial structuring in determining and calculating quantities as a progression from counting unitarily (Geary, 1994; Carr and Hettinger, 2003; Siegler and Booth, 2005; Van Nes and de Lange, 2007; Ramani and Siegler, 2008; Van Nes and Doorman, 20I I; Wade, 20I I).

With the reports of a positive effect of active music-making on spatial-temporal reasoning and spatial-temporal reasoning being instrumental in many mathematical operations, the current research sets out to explore the impact of participation in music on the development of spatial-temporal skills. This study aimed to investigate whether learning music might also have the potential to improve pupils' achievement in mathematics and whether spatialtemporal reasoning plays a role in this process. The possibility of the music programme affecting learning mathematics in other ways than through spatial-temporal reasoning was also considered. The research questions addressed in the study reported here were: does participation in music improve spatial-temporal reasoning; how, if at all, does participation in music influence learning in mathematics; and what is the relationship between spatialtemporal and mathematical skills?

\section{Method and measurements}

The study had a quasi-experimental design in which groups of children aged 4 to 7 participated in a music programme over a period of two years. These age groups were chosen because according to findings from previous studies, the most pronounced enhancement of skills was observed in younger participants of early primary school age (Graziano et al., 1999; Costa-Giomi, 2000; Rauscher and Zupan, 2000; Schellenberg, 2004; Hallam, 20I5). The pilot study involved I 20 children from Year I (YrI) and Foundation Stage (FS). The parents of the pupils were informed about the project and gave consent to their children's involvement. Within each of the two year groups, 30 randomly chosen pupils took part in the music intervention, while the other 30 made up the control group. In the main study this number 
grew to 178 pupils, with children from the pilot study continuing the music programme, and the additional children forming the new intake. At the beginning of each academic year, each year cohort was mixed and new classes were set so children were taught by different teachers. This reduced the potential bias related to being taught by a particular teacher. The intervention took place weekly during the school day. Sessions lasted 30 minutes and were delivered to groups of about 15 children. Pupils from the control groups followed their usual school timetable, with activities such as school assembly, ICT, group reading and role play. Table I presents the design of the study.

Table I: Stages of the study, participating groups and numbers of students involved in the project

\begin{tabular}{|c|c|c|}
\hline Stage of the research & Grouping & Participants \\
\hline \multirow{2}{*}{$\begin{array}{l}\text { Pilot study } \\
\text { (first year of the study) }\end{array}$} & intervention in $\mathrm{FS}$ and $\mathrm{Yr} \mathrm{I}$ & 60 students \\
\hline & control group in FS and $\mathrm{YrI}$ & 60 students \\
\hline \multirow[t]{2}{*}{$\begin{array}{l}\text { Main study } \\
\text { (second year of the study) }\end{array}$} & intervention in $\mathrm{FS}, \mathrm{Yr} /$ and $\mathrm{Yr} 2$ & $\begin{array}{c}\text { the same } 60+30 \text { new } \\
\text { students in FS }\end{array}$ \\
\hline & control group in $\mathrm{FS}, \mathrm{YrI}$ and $\mathrm{Yr} 2$ & $\begin{array}{c}\text { the same } 60+28 \text { new } \\
\text { students in FS }\end{array}$ \\
\hline
\end{tabular}

To ensure the external validity of the study, the school chosen to participate in the project needed to be representative of English primary schools. Several criteria relating to the school's characteristics and academic attainment were taken into account. Data from the school were compared with national data. This included results from the SATs, which is a national test in English and mathematics sat by all pupils at the end of primary school (at II years old). Over 70 per cent of pupils from the participating school achieved Level 4 or above in both English and mathematics in 20II, which was very close to the national average of 74 per cent; 95 per cent of pupils reached the expected level of progress in English and 91 per cent in mathematics, compared to the national average of 89 per cent and 87 per cent. Numerical assessment of pupils' progress, which is moderated across England, showed an average point score of 28.3 at the participating school, as opposed to 27.6 nationally. The percentages of children with special educational needs and disabilities (SEND), children eligible for free school meals and persistent absence in the school were also very similar to national averages.

The music programme created for the current study was built on findings from previous research. Most of this suggested that rhythmic activities have the strongest impact on spatialtemporal reasoning (Hetland, 2000; Rauscher, 2003; Rauscher and LeMieux, 2003; Rauscher and Hinton, 2006) and such instruction was at the core of the intervention. It also attempted to address the implications from a study by Hallam and colleagues (2009) that many teachers do not feel well prepared to lead music lessons, and that even a day of specific training can bring about a significant change in teachers' confidence and attitudes towards music. In a review of music education, Henley (20 I I) stated that music provision was inconsistent, and proposed a number of recommendations to improve the quality of music for all children. In view of these findings, the programme contained activities that could be implemented by primary teachers who were not specialists in music. The programme was suited to the circumstances of most primary schools, as it did not require any additional equipment, apart from widely available untuned percussion instruments, while its intensity was similar to music occurring in schools at present. Compliance with the requirements of the UK national curriculum ensured that the programme might be used in a wider educational context. 
The intervention was focused on rhythmic instruction, with elements of singing, learning to read musical notation and creating music. Most units were based on well-known nursery rhymes, as teachers would be familiar with them and more confident in singing them in front of the class. The beats and rhythms of these songs were then reproduced by voice, clapping, stomping and on untuned percussion instruments, in groups and individually. This led to further rhythmic exercises, which included maintaining a steady beat; clapping and tapping rhythms; recalling and reproducing rhythms; creating rhythms within different time signatures; performing simple polyrhythms; using rhythmic patterns to create and perform simple structures such as rounds, ternary form and rondo; movement with rhythm; and playing untuned percussion instruments alone and in group arrangements. Children learned some musical terms and their meanings and elements of musical notation, and gained some knowledge of the science of sound. These weekly sessions were arranged during the school day, lasted 30 minutes, and were based in the music room.

Throughout the intervention, pupils' individual attainment in mathematics, reading, writing, music and spatial-temporal tests was recorded and compared with the same measurements for the control groups. Mathematics, reading and writing were assessed by the class teachers, while spatial-temporal and musical abilities were assessed by the researcher. Spatial-temporal reasoning was assessed in two ways - through picture and puzzle tests. The picture test consisted of four pieces of a puzzle, which needed to be put together to form a picture of an elephant. The picture was not provided, so the children had to create a mental image, rotate the pieces, and put them together in a particular order to complete the task. The puzzle test consisted of a set of colourful blocks, which needed to be ordered on a rectangular-shaped base as prescribed in the template. The time it took to complete both tasks was recorded in seconds and became the variables 'picture test' and 'puzzle test' respectively. In music, children were assessed throughout the year against a set of skills, and the sum of these scores was used in the analyses.

Pupils' results in reading and writing were used as a control for a possible Hawthorne effect. The assumption was that if statistically significant differences in performance between different groups were recorded in mathematics, but not in other areas of assessment (reading or writing), then it was likely that this was a result of the participation in the music programme, rather than just of involvement in any intervention. These scores also enabled an additional investigation into the possible causality between the intervention and the impact on attainment in mathematics. Apart from comparing the music and the control groups, data from reading and writing tests were used to further compare whether any statistically significant progressions for the intervention groups were existent throughout all areas of learning or were specific to mathematics.

Three sets of quantitative data were collected from the intervention groups. They were: performance on spatial-temporal reasoning, which children completed at the beginning of the programme and at the end of each year; data from teachers' assessments in mathematics, reading and writing at the end of each academic year; and data from the assessment of children's musical skills occurring throughout the school year. Only the first two sets of data were collected from the control groups, as they did not participate in the music programme. Although teachers knew which children took part in the intervention, the assessment and marking throughout the school was prescribed in much detail and scrutinized by internal and external moderation, which prevented any possible bias. The analyses were undertaken in three stages:

- The pilot study (which was the first year of the intervention).

- The main study (the second year of the intervention for the two older groups, and the first year for the group of 30 children new to the school in Foundation Stage). 
- Scores combined from both years of the intervention divided into year groups: scores achieved while the children were in Year I, and the results of the children from the Foundation Stage (FS).

\section{Results}

The purpose of this study was to explore the potential effect of participation in music on the development of spatial-temporal skills, and to examine whether learning music might lead to improvement in pupils' achievement in mathematics. The research also investigated whether spatial-temporal reasoning played a role in the relationship between music and mathematics. The possible impact of the intervention on spatial-temporal reasoning and mathematics was investigated by the analyses of the results in both of these areas and comparisons of the differences between the music and control groups. The examination of the scores in reading and writing provided further information about the causational nature of the above impact and served as a control for the Hawthorne effect.

\section{The effects of participation in music on scores in spatial-temporal tests}

Pupils' spatial-temporal skills were tested individually at the beginning of the intervention and at the end of each academic year. Because the level of difficulty changed for each year group, these results were analysed separately for each class. Once the scores in spatial-temporal tests were considered, the intervention groups achieved greater results than their peers in one or both spatial-temporal tests in all but one assessment in all periods of measurement. To check whether these differences between groups were statistically significant, independentsamples t-tests were conducted for all times of assessment. The results showed that there were no statistically significant differences between groups at the beginning of the intervention. Statistically significant differences at the end of the year were recorded at the end of the pilot study, when the FS music group outperformed their peers in the puzzle test $t(59)=2.697$, $\mathrm{p}=.0 \mathrm{I}$. Statistically significant results were also recorded for both music groups for the puzzle test, once the results were combined from both years of the study, with $t(I I 8)=2.473, p=.015$ for the $\mathrm{YrI}$ group, and $\mathrm{t}(\mathrm{I}$ I7) $=2.052, \mathrm{p}=.042$ for the FS group.

This was followed by the analyses of the differences in progression, to investigate the possible effect of the music programme on children's spatial-temporal skills. To assess the impact of the intervention versus belonging to the control group over time, a repeated measures analysis was used. These analyses were undertaken for the different age groups in different areas of measurement, across two time periods (Cramer and Howitt, 2004; Tabachnick and Fidell, 200I). Table 2 summarizes the outcomes of these analyses for the picture and puzzle tests at different points in the study. For the picture test, a greater change of scores for the intervention groups was statistically significant in all periods of measurement for the FS groups and in the pilot study for the $\mathrm{Yrl}$ class. For the puzzle test, statistically significant greater progression for the music groups was recorded in all periods of measurement for the Yrl groups and in the pilot study and the combined results for the FS groups. These occurrences are marked grey in the table. The strength of these relationships was stronger for the picture test and weaker for the puzzle test, in particular once the combined scores were considered. 
Table 2: Assessments in spatial-temporal tests in which the change in scores over time for the intervention groups was greater than for the controls

\begin{tabular}{lcc|ccc|cc} 
& \multicolumn{2}{c}{ Pilot study } & \multicolumn{3}{c}{ Main study } & \multicolumn{2}{c}{ Combined classes } \\
\cline { 2 - 8 } & Yr $\boldsymbol{I}$ & FS & Yr2 & YrI & FS & YrI & FS \\
\hline Picture & $\mathrm{P}=.006$ & $\mathrm{P}=.005$ & $\mathrm{P}=.456$ & $\mathrm{P}=.117$ & $\mathrm{P}=.003$ & $\mathrm{P}=.313$ & $\mathrm{P}=.000$ \\
test & $\eta_{p}^{2}=.125$ & $\eta_{p}^{2}=.126$ & $\eta_{p}^{2}=.010$ & $\eta_{p}^{2}=.041$ & $\eta_{p}^{2}=.144$ & $\eta_{p}^{2}=.009$ & $\eta_{p}^{2}=.132$ \\
\hline Puzzle & $\mathrm{P}=.041$ & $\mathrm{P}=.026$ & $\mathrm{P}=.312$ & $\mathrm{P}=.012$ & $\mathrm{P}=.506$ & $\mathrm{P}=.021$ & $\mathrm{P}=.04 \mathrm{I}$ \\
test & $\eta_{p}^{2}=.071$ & $\eta_{p}^{2}=.087$ & $\eta_{p}^{2}=.018$ & $\eta_{p}^{2}=.103$ & $\eta_{p}^{2}=.008$ & $\eta_{p}^{2}=.045$ & $\eta_{p}^{2}=.031$ \\
\hline
\end{tabular}

\section{The effects of participation in music on attainment in general mathematics}

The differences between groups, pre- and post-intervention, were also analysed in mathematics. The results of the independent-samples t-tests showed that at the beginning of the programme, the $\mathrm{YrI}$ music group achieved statistically significantly lower scores $(\mathrm{t}(57)=-2.063, \mathrm{p}=.044$ (two-tailed)), but at the end of the intervention no such differences between groups were observed. However, the magnitude of this difference was not substantial enough to make it statistically significant in repeated measures analysis. In the main study, there were no statistically significant differences pre-intervention between any of the groups of respective ages. By the end of the year, the FS music group statistically significantly outperformed their peers $(\mathrm{t}(57)=2.164$, $\mathrm{p}=.036)$. No other statistically significant differences pre- and post-intervention were recorded in mathematics.

Further analyses investigated the differences in progression between the groups. To investigate the impact of belonging to the intervention versus the control group over time in mathematics, a repeated measures analysis was used for the different age groups pre- and post-intervention. The results of these analyses showed that statistically significantly greater progression was recorded for the children from the youngest intervention groups in two out of three periods of measurement, compared to their peers from the control group. The effect size was moderate for the youngest group in the main study $(p=.032$, partial eta squared $=.079)$ and smaller for the combined group of all children from Foundation Stage who took part in music lessons $(\mathrm{p}=.035$, partial eta squared $=.037)$. The results of the analyses at different points in time are set out in Table 3, and the statistically significant cases are marked in grey.

Table 3: Assessments in mathematics in which the change in scores over time for the intervention groups was statistically significantly greater than for the controls

\begin{tabular}{ccc|ccc|cc} 
& \multicolumn{2}{c}{ Pilot study } & \multicolumn{3}{c}{ Main study } & \multicolumn{2}{c}{ Combined classes } \\
\cline { 2 - 8 } & YrI & FS & Yr2 & Yr $\boldsymbol{F}$ & FS & YI & FS \\
\hline Maths & $\mathrm{P}=.140$ & $\mathrm{P}=.486$ & $\mathrm{P}=.372$ & $\mathrm{P}=.167$ & $\mathrm{P}=.032$ & $\mathrm{P}=.461$ & $\mathrm{P}=.035$ \\
& $\eta_{p}^{2}=.036$ & $\eta_{p}^{2}=.008$ & $\eta_{p}^{2}=.014$ & $\eta_{p}^{2}=.032$ & $\eta_{p}^{2}=.079$ & $\eta_{p}^{2}=.004$ & $\eta_{p}^{2}=.037$ \\
\hline
\end{tabular}

\section{Changes in scores for the intervention and control groups in reading and writing}

Similar repeated measures analyses of progression between the music and the control groups were undertaken for scores in reading and writing at each of the periods of measurement. These analyses served as a control for a possible Hawthorne effect. The results showed that there 
were no statistically significant differences between groups in writing at any point of the study. The statistically significant change of scores in reading was greater for the FS music groups in the pilot study $(p=.00 \mathrm{I}$, partial eta squared $=.208)$ and, once the combined results from both years of the study were considered $(p=.003$, partial eta squared $=.07 \mathrm{I})$, with strong and moderate effect sizes respectively. It was also the case for the Yr2 class in the main study $(p=.019$, partial eta squared $=.092$ ). As the statistically significant differences are not aligned with these in mathematics, it can be assumed that the impact of the programme was not a Hawthorne affect. The results of these analyses are presented in Table 4.

Table 4: Assessments in reading and writing in which the change in scores over time for the intervention groups was statistically significantly greater than for the controls

\begin{tabular}{ccc|ccc|cc} 
& \multicolumn{2}{c}{ Pilot study } & \multicolumn{3}{c}{ Main study } & \multicolumn{2}{c}{ Combined classes } \\
\cline { 2 - 8 } & YrI & FS & Yr2 & YrI & FS & YI & FS \\
\hline Reading & $\mathrm{P}=.612$ & $\mathrm{P}=.001$ & $\mathrm{P}=.019$ & $\mathrm{P}=.61 \mathrm{I}$ & $\mathrm{P}=.267$ & $\mathrm{P}=.628$ & $\mathrm{P}=.003$ \\
& $\eta_{p}^{2}=.004$ & $\eta_{p}^{2}=.208$ & $\eta_{p}^{2}=.092$ & $\eta_{p}^{2}=.004$ & $\eta_{p}^{2}=.022$ & $\eta_{p}^{2}=.002$ & $\eta_{p}^{2}=.071$ \\
\hline \multirow{2}{*}{ Writing } & $\mathrm{P}=.774$ & $\mathrm{P}=.446$ & $\mathrm{P}=.445$ & $\mathrm{P}=.191$ & $\mathrm{P}=.210$ & $\mathrm{P}=.596$ & $\mathrm{P}=.412$ \\
& $\eta_{p}^{2}=.001$ & $\eta_{p}^{2}=.010$ & $\eta_{p}^{2}=.010$ & $\eta_{p}^{2}=.029$ & $\eta_{p}^{2}=.028$ & $\eta_{p}^{2}=.002$ & $\eta_{p}^{2}=.006$ \\
\hline
\end{tabular}

\section{Discussion}

Previous investigations have provided compelling evidence that actively making music develops a variety of abilities in participants. The enhancement of spatial-temporal skills was observed in several studies, and the current research set out to further examine this phenomenon and establish the possibility of its causational nature. As these abilities are considered to be highlevel mathematical skills (Shaw, 2000; Gunderson et al., 20I2), a hypothesis was proposed that through a positive impact on spatial-temporal reasoning, it is possible that participation in the music programme would have an effect on learning mathematics.

As the participation in this intervention was likely to have been beneficial to pupils, it was decided that the music programme should be created, to enable it being used in a wider educational context. Adversely to previous studies, which used expensive resources or professional musicians, this intervention was accessible for primary teachers who are not music specialists, and was designed to support the development of their music-teaching skills.

The results from the current study supported the hypothesis that actively learning music has a positive impact on the development of spatial-temporal skills. Statistically significant differences between the intervention and the control groups, with the greater achievement in the music groups, were observed at the end of each academic year for the puzzle test. This was an activity that required more complex spatial-temporal reasoning. When the change in scores for the spatial-temporal tests was analysed and compared between the music and the control groups, greater progression was recorded for the intervention groups and most of these differences were statistically significant with moderate or strong effect sizes. In the pilot study, a statistically significant change of scores in both spatial-temporal tests were recorded for both the FS music and YrI music groups. In the main study, both of the younger groups achieved statistically significantly greater progression in one of the tests. The combined results showed that progression, in both music groups in one or both tests, was statistically significant and greater than that for their control peers. These findings support the proposition that participation in music has an impact on the enhancement of spatial-temporal skills. 
Throughout the study, the performance of groups of children who took part in the music programme was compared with the control group in the area of general mathematics. Findings from the analyses showed that in mathematics the interaction between participation in the music programme and academic achievement was less clear than the impact on spatial-temporal reasoning. There were some statistically significant differences between the intervention and the control groups in the pilot study, where the $\mathrm{YrI}$ music group started the year with statistically lower results and after a year of the intervention the difference between groups was no longer statistically significant. This change was not pronounced enough to be confirmed in the repeated measures analysis. Within the youngest groups, however, the intervention groups consistently achieved greater progress than their peers. These results were statistically significant for the FS group in the main study and the FS group once the results from all FS groups were combined. This effect was more marked in the younger children, supporting the findings from the previous studies that the earlier children start music instruction, the more pronounced an impact it will have on their development (Hetland, 2000; Rauscher and Zupan, 2000; Rauscher, 2003; Rauscher and Hinton, 20I I; McDonel, 20I5).

The current study investigated whether the impact music had on the advancement of spatial-temporal skills contributed to the development of mathematical thinking. The analyses revealed cases where the intervention groups were better than the controls in spatialtemporal tests, but not in mathematics, especially in the groups of older children. This suggests that the relationship between active participation in music and the learning of mathematics is more complex than a general effect on academic attainment. In all cases where a statistically significant difference was observed in mathematics, the differences for the same groups were also statistically significant in spatial-temporal tests, which supports the hypothesis that spatial-temporal reasoning plays a mediating role in the relationship between learning music and mathematics. These findings might be related to the age of children and confirm the previous findings that the development of spatial-temporal skills is more distinct in younger children. This might also be true of the enhancement of mathematical skills. It is also possible that the development of spatial-temporal skills had an impact on specific mathematical skills rather than on the overall scores in mathematics. To investigate this proposition, throughout the duration of the study supplementary data related to specific mathematical and musical skills were collected. The analyses of these results are being prepared for publication and they will provide further examination of these correlations.

The results of the current research supported the hypothesis that active participation in the music programme had a positive impact on learning in mathematics, but it was important to establish if this was an effect of this music intervention specifically or the presence of any intervention. To further explore this possibility, pupils' results in reading and writing were also collected throughout the study and analysed. While participation in the music intervention influenced some scores in mathematics and in reading, only one of these statistically significant results occurred for the same group in the same periods of measurement. This, and the fact that no statistically significant effects were observed in writing, suggests that the effect was specific rather than general, and it is likely that there was a causal relationship between the musical instruction and achievement in mathematics. These differences also suggest that the music programme positively enhanced pupils' reading skills, which supports findings from previous studies (Good et al., 2002; Standley, 2008; Elliot and Mikulas, 20I4; Long, 20I4). The fact that there were no statistically significant differences in progression in writing between the intervention and the control groups is an unexpected finding of this study. It contributes to rather limited literature describing the influence of music on writing skills, which is inconclusive: 
two studies suggest a positive enhancement (Register, 200I; Register, 2004) and another one found a negative effect (Rickard et al., 20I2).

This project was not without its limitations. For a quantitative study, the research had a relatively small sample, which on occasion limited the statistical analyses that could be undertaken. The sample size was, however, appropriate for comparisons to be made between the intervention and control groups. The form of assessment in school subjects was different in Foundation Stage classes from that in Year I classes, which meant that the results had to be analysed separately, leading to decreased sample size. The programme was limited to using predominantly rhythmic instruction. A conscious decision was made regarding this, as previous research suggested that rhythm was most effective in developing spatial-temporal skills. The intervention was intentionally simplified in terms of the musical skills required from the teachers, while potentially a more advanced musical approach might have had a more distinct effect. However, enabling non-specialist music teachers to implement the activities in their lessons was considered an important outcome. Also, incorporating teacher-led assessment, driven by the national curriculum, was an important element of the project. It was considered that this might enhance the validity of the research, as the assessment was undertaken by objective professionals not related to the project, and facilitate the replication of the study in other educational settings. The continuous internal and external moderation of these assessments additionally ensured objectivity and reliability.

The intervention used in the current study was created not only to investigate the possible impact of music on mathematics but also to propose a music programme accessible for primary teachers who are not music specialists. At the moment, many teachers are not comfortable teaching music. Limited training time and the broad requirements of the curriculum, which can be open to interpretation, make it difficult for non-specialist teachers to access programmes to study, let alone to teach confidently. Teachers are not prepared to plan for progression in music, and struggle with assessing pupils' competencies. All these issues are addressed in this music programme, and further research is required to investigate whether such a programme delivered by teachers on regular bases, not just as an intervention, would still be beneficial for the learning of mathematics.

As the sample in the current study was restricted to one school, it would be beneficial to obtain more data and enable more detailed analyses from a study based on similar methodology with a larger number of pupils from different areas of the UK. In this project, the impact of the intervention was greater in younger children and it would also be advisable to create a simplified version of the programme to use in FS3 and FS2, and to examine the outcomes for these pupils.

To conclude, the findings of the current project supported the previous findings about the impact of music instruction on the development of spatial-temporal skills. In most of the intervention groups, a statistically significantly greater progression was observed as compared to the control groups. In addition to earlier studies, this research also explored the possibility that the enhancement of spatial-temporal reasoning facilitates the learning of mathematics. The attainment in general mathematics did not always differ between the intervention and control groups, but there was a consistent and statistically significant enhancement in learning mathematics between the youngest participants of the programme. This knowledge could inform pedagogical practice, while further research in this area, following the potential directions indicated above, could offer more insight into the association between music and mathematics. 


\section{Notes on the contributors}

Dr Sylwia Holmes is a research associate at the UCL Centre for Holocaust Education. Her work concentrates on the impact learning about the Holocaust has on students. She has 20 years of teaching experience, with specialism in music and physical education. Her doctoral work examines the impact of participation in music on learning mathematics in young children.

Susan Hallam is Professor of Education and Music Psychology at University College London. She is author of numerous books, including Instrumental Teaching: A practical guide to better teaching and learning (Heinemann, 1998), Music Psychology in Education (Institute of Education, 2006), Preparing for Success: A practical guide for young musicians (Institute of Education, 2012) and The Power of Music: A research synthesis (iMerc Press, 20I5).

\section{References}

Booth, J.L. and Siegler, R.S. (2008) 'Numerical magnitude representations influence arithmetic learning'. Child Development, 79 (4), 1016-31.

Carr, M. and Hettinger, H. (2003) 'Perspectives on mathematics strategy development'. In Royer, J.M. (ed.) Mathematical Cognition. Greenwich, CT: Information Age Publishing, 33-68.

Costa-Giomi, E. (1999) 'The effects of three years of piano instruction on children's cognitive development'. Journal of Research in Music Education, 47 (3), 198-212.

Costa-Giomi, E. (2000) 'The relationship between absolute pitch and spatial abilities'. In Woods, C., Luck, G., Brochard, R., Seddon, F. and Sloboda, J. (eds) Proceedings of the Sixth International Conference on Music Perception and Cognition. Keele: Department of Psychology, University of Keele, 47-62.

Costa-Giomi, E. (2004) 'Effects of three years of piano instruction on children's academic achievement, school performance and self-esteem'. Psychology of Music, 32 (2), 139-52.

Cramer, D. and Howitt, D. (2004) The Sage Dictionary of Statistics. London: Sage.

Elliot, S. and Mikulas, C. (20/4) 'A study of the effectiveness of music technology integration on the development of language and literacy skills'. In Searson, M. and Ochoa, M. (eds) Proceedings of the Society for Information Technology and Teacher Education International Conference 2014. Chesapeake, VA: Association for the Advancement of Computing in Education, 1883-90.

Gardiner, M.F., Fox, A., Knowles, F. and Jeffrey, D. (1996) 'Learning improved by arts training'. Nature, 38I, 284.

Geary, D.C. (1994) Children's Mathematical Development: Research and practical applications. Washington, DC: American Psychological Association.

Geist, K., Geist, E.A. and Kuznik, K. (2012) 'The patterns of music: Young children learning mathematics through beat, rhythm, and melody'. Young Children, 67 (I), 74-9.

Good, R.H., Gruba, J. and Kaminski, R.A. (2002) 'Best practices in using Dynamic Indicators of Basic Early Literacy Skills (DIBELS) in an outcomes-driven model'. In Thomas, A. and Grimes, J. (eds) Best Practices in School Psychology IV (Vol. I). Bethesda, MD: National Association of School Psychologists, 699-720.

Graziano, A.B., Peterson, M. and Shaw, G.L. (1999) 'Enhanced learning of proportional math through music training and spatial-temporal training'. Neurological Research, 2I (2), I39-52.

Gunderson, E.A., Ramirez, G., Beilock, S.L. and Levine, S.C. (2012) 'The relation between spatial skill and early number knowledge: The role of the linear number line'. Developmental Psychology, 48 (5), |229-4|.

Hallam, S. (2000) 'The effects of listening to music on children's spatial task performance'. British Psychological Society Education Review, 25 (2), 22-6.

Hallam, S. (2015) The Power of Music: A research synthesis of the impact of actively making music on intellectual, social and personal development of children and young people. London: International Music Education Research Centre. 
Hallam, S., Creech, A. and Papageorgi, I. (2009) EMI Music Sound Foundation: Evaluation of the impact of additional training in the delivery of music at Key Stage I. London: Institute of Education. Online. http:// eprints.ioe.ac.uk/2299 (accessed 16 June 2016).

Hallam, S., Cross, I. and Thaut, M. (eds) (201I) The Oxford Handbook of Music Psychology. Oxford: Oxford University Press.

Henley, D. (20II) The Importance of Music: A national plan for music education. London: Department for Education Publications. Online. www.gov.uk/government/uploads/system/uploads/attachment_data/ file/ I 80973/DFE-00086-20 I I.pdf (accessed I4 January 20 I5).

Hetland, L. (2000) 'Learning to make music enhances spatial reasoning'. Journal of Aesthetic Education, $34(3-4), 179-238$.

Jordan, N.C., Glutting, J. and Ramineni, C. (2008) 'A number sense assessment tool for identifying children at risk for mathematical difficulties'. In Dowker, A. (ed.) Mathematical Difficulties: Psychology and intervention. London: Academic Press, 45-58.

Long, M. (2014) “'I can read further and there's more meaning while I read”: An exploratory study investigating the impact of a rhythm-based music intervention on children's reading'. Research Studies in Music Education, 36 (I), 107-24.

McDonel, J.S. (2015) 'Exploring learning connections between music and mathematics in early childhood'. Bulletin of the Council for Research in Music Education, 203, 45-62.

Neville, H., Andersson, A., Bagdade, O., Bell, T., Currin, J., Fanning, J., Klein, S., Lauinger, B., Pakulak, E., Paulsen, D., Sabourin, L., Stevens, C., Sundborg, S. and Yamada, Y. (2008) 'Effects of music training on brain and cognitive development in under-privileged 3- to 5-year-old children: Preliminary results'. In Asbury, C. and Rich, B. (eds) Learning, Arts, and the Brain: The Dana Consortium report on arts and cognition. New York: Dana Press, 105-16.

Rafferty, K.N. (2003) Will a Music and Spatial-Temporal Math Program Enhance Test Scores? An analysis of second-grade students' mathematics performance on the Stanford-9 Test and the Capistrano Unified School District CORE Level Test.' EdD thesis, University of Southern California.

Ramani, G.B. and Siegler, R.S. (2008) 'Promoting broad and stable improvements in low-income children's numerical knowledge through playing number board games'. Child Development, 79 (2), 375-94.

Rauscher, F.H. (2002) 'Mozart and the mind: Factual and fictional effects of musical enrichment'. In Aronson, J. (ed.) Improving Academic Achievement: Impact of psychological factors on education. London: Academic Press, 267-78.

Rauscher, F.H. (2003) 'Effects of piano, singing, and rhythm instruction on the spatial reasoning of atrisk children'. Paper presented at the 5th Triennial Conference of the European Society for the Cognitive Sciences of Music (ESCOM), Hanover University of Music and Drama, Hanover, Germany, 8-13 September 2003.

Rauscher, F.H. and Hinton, S.C. (2006) 'The Mozart effect: Music listening is not music instruction'. Educational Psychologist, 4I (4), 233-8.

Rauscher, F.H. and Hinton, S.C. (20II) 'Music instruction and its diverse extra-musical benefits'. Music Perception, 29 (2), 2I5-26.

Rauscher, F.H. and LeMieux, M.T. (2003) 'Piano, rhythm, and singing instruction improve different aspects of spatial-temporal reasoning in Head Start children'. Poster presented at the Annual Meeting of the Cognitive Neuroscience Society, New York, 29 March-I April 2003.

Rauscher, F.H., LeMieux, M. and Hinton, S.C. (2005) 'Selective effects of music instruction on cognitive performance of at-risk children'. Paper presented at the I 2th European Conference on Developmental Psychology, Tenerife, 24-28 August 2005.

Rauscher, F.H., Shaw, G.L. and Ky, K.N. (1993a) 'Music and spatial task performance'. Nature, 365 (6447), 611.

Rauscher, F.H., Shaw, G.L., Levine, L.J. and Wright, E.L. (1993b) 'Pilot study indicates music training of three-year-olds enhances specific spatial reasoning skills'. Paper presented at the Economic Summit of the National Association of Music Merchants, Newport Beach, CA.

Rauscher, F.H., Shaw, G.L., Levine, L.J., Wright, E.L., Dennis, W.R. and Newcomb, R.L. ( 1997) 'Music training causes long-term enhancement of preschool children's spatial-temporal reasoning'. Neurological Research, 19, 2-8. 
Rauscher, F.H. and Zupan, M.A. (2000) 'Classroom keyboard instruction improves kindergarten children's spatial-temporal performance: A field experiment'. Early Childhood Research Quarterly, I5 (2), 2I 5-28.

Register, D. (200I) 'The effects of an early intervention music curriculum on prereading/writing'. Journal of Music Therapy, 38 (3), 239-48.

Register, D. (2004) 'The effects of live music groups versus an educational children's television program on the emergent literacy of young children'. Journal of Music Therapy, 4I (I), 2-27.

Rickard, N.S., Bambrick, C.J. and Gill, A. (20I2) 'Absence of widespread psychosocial and cognitive effects of school-based music instruction in 10-13-year-old students'. International Journal of Music Education, 30 (I), 57-78.

Schellenberg, E.G. (2004) 'Music lessons enhance IQ'. Psychological Science, I5 (8), 5 I I-I4.

Shaw, G.L. (2000) Keeping Mozart in Mind. San Diego, CA: Academic Press.

Siegler, R.S. and Booth, J.L. (2005) 'Development of numerical estimation: A review'. In Campbell, J.I.D. (ed.) Handbook of Mathematical Cognition. Hove: Psychology Press, 197-212.

Standley, J.M. (2008) 'Does music instruction help children learn to read? Evidence of a meta-analysis'. Update: Applications of Research in Music Education, 27 (I), I7-32.

Tabachnick, B.G. and Fidell, L.S. (200I) Using Multivariate Statistics. London: Pearson.

Van Nes, F. and de Lange, J. (2007) 'Mathematics education and neurosciences: Relating spatial structures to the development of spatial sense and number sense'. Mathematics Enthusiast, 4 (2), 210-29.

Van Nes, F. and Doorman, M. (20II) 'Fostering young children's spatial structuring ability'. International Electronic Journal of Mathematics Education, 6 (I), 27-39.

Wade, C.E. (20II) 'Exploring the Development of Mathematics Patterning Skills and Concepts in Young Children Who Experience Integrated Music and Math Lessons.' EdD thesis, University of Houston. Online. https://uh-ir.tdl.org/uh-ir/bitstream/handle//0657/253/WADE-.pdf?sequence=2 (accessed 5 April 2016).

Yang, H., Ma, W., Gong, D., Hu, J. and Yao, D. (20I4) 'A longitudinal study on children's music training experience and academic development'. Scientific Reports, 4 (5854), I-7.

\section{Related articles published in the London Review of Education}

The paper was published in a special feature of the journal called: 'Music education in context', edited by Hilary McQueen and Maria Varvarigou. The other articles in the feature are:

Black, P. (2017) 'On being and becoming a jazz musician: Perceptions of young Scottish musicians'. London Review of Education, I5 (3), 339-57.

Cooper, N. (2017) 'Design-based research as an informal learning model for choral conductors'. London Review of Education, I5 (3), 358-7I.

Gande, A. and Kruse-Weber, S. (2017) 'Addressing new challenges for a community music project in the context of higher music education: A conceptual framework'. London Review of Education, I5 (3), 372-87.

Hallam, S. (2017) 'The impact of making music on aural perception and language skills: A research synthesis'. London Review of Education, 15 (3), 388-406.

Hart, A. (2017) 'Towards an effective freeware resource for music composition in the primary classroom'. London Review of Education, 15 (3), 407-24.

Johnson, C. (2017) 'Teaching music online: Changing pedagogical approach when moving to the online environment'. London Review of Education, 15 (3), 439-56. 
Minors, H.J., Burnard, P., Wiffen, C., Shihabi, Z. and van der Walt, J.S. (2017) 'Mapping trends and framing issues in higher music education: Changing minds/changing practices'. London Review of Education, 15 (3), 457-73.

Rodgers, D. (2017) 'Community music as a vehicle for tackling mental health-related stigma'. London Review of Education, 15 (3), 474-87.

Sarazin, M. (2017) 'Can student interdependence be experienced negatively in collective music education programmes? A contextual approach'. London Review of Education, I5 (3), 488-504. 